\title{
TurtleWatch: a tool to aid in the bycatch reduction of loggerhead turtles Caretta caretta in the Hawaii-based pelagic longline fishery
}

\author{
Evan A. Howell ${ }^{1, *}$, Donald R. Kobayashi ${ }^{1,2}$, Denise M. Parker ${ }^{1,3}$, George H. Balazs ${ }^{1}$, \\ Jeffrey J. Polovina ${ }^{1}$
}

${ }^{1}$ Pacific Islands Fisheries Science Center, National Marine Fisheries Service, National Oceanic and Atmospheric Administration, U.S. Department of Commerce, 2570 Dole Street, Honolulu, Hawaii 97822-2396, USA

${ }^{2}$ Department of Environmental Sciences, University of Technology, Sydney, Broadway, New South Wales 2007, Australia

${ }^{3}$ Joint Institute for Marine and Atmospheric Research, 1000 Pope Road, University of Hawaii, Honolulu, Hawaii 96822-2396, USA

\begin{abstract}
Operational longline fishery characteristics, bycatch information, and loggerhead turtle satellite tracks were all used in conjunction with remotely sensed sea surface temperature data to identify the environmental area where the majority of loggerhead turtle bycatch occurred in the Hawaii-based longline fishery during 1994 to 2006. In the first quarter of each calendar year from 1994 to 2006, the majority of shallow longline sets and associated loggerhead turtle bycatch were above $28^{\circ} \mathrm{N}$, which corresponds to the area near the North Pacific Subtropical Frontal Zone. Based on the thermal ranges of bycatch, sets and the satellite-tagged turtles, it was recommended that shallow sets should only be deployed in waters south of the $18.5^{\circ} \mathrm{C}\left(\sim 65.5^{\circ} \mathrm{F}\right)$ isotherm to decrease loggerhead turtle bycatch. This recommendation formed the basis for the TurtleWatch tool, a map providing up-to-date information about the thermal habitat of loggerhead sea turtles in the Pacific Ocean north of the Hawaiin Islands. TurtleWatch was released to fishers and managers in electronic and paper formats on December 26, 2006, to assist in decision making during the first quarter of 2007. Fishery information from 2007 was later compared with data for the years 2005 to 2006 to assess the response of the fishery to TurtleWatch. The observed fleet movement during the first quarter of 2007 was to the north of the $18.5^{\circ} \mathrm{C}\left(\sim 65.5^{\circ} \mathrm{F}\right)$ isotherm (i.e. in the area recommended for avoidance by the TurtleWatch product) with increased effort and lower bycatch rates. We discuss possible reasons for this decrease in turtle bycatch north of the frontal zone together with future research directions which may lead to refinement of the TurtleWatch product.
\end{abstract}

KEY WORDS: Loggerhead turtles $\cdot$ Bycatch $\cdot$ Remote-sensing $\cdot$ Sea surface temperature $\cdot$ Longline fishery $\cdot$ Transition zone $\cdot$ Swordfish

Resale or republication not permitted without written consent of the publisher

\section{INTRODUCTION}

The interactions of sea turtles with high seas fisheries are a global concern, with fisheries bycatch implicated as one of several factors in the population decline of many sea turtle species, including the loggerhead turtle Caretta caretta (Hatase et al. 2002, Hays et al. 2003, Peckham et al. 2007). The loggerhead is a circumglobal sea turtle species (Dodd 1988) that undergoes a series of ontogenetic shifts during its life cycle, with stages occupying a series of habitats that include nesting beach, oceanic, and neritic areas (Bjorndal 2003). In the North Pacific, loggerhead nesting beaches are only found in Japan, where, during the last half of the 20th century a substantial decline (50 to $90 \%$ ) in the size of the annual loggerhead nesting population at nesting beaches was reported (Kamezaki et al. 2003). The importance of the oceanic stage to juvenile loggerheads was hypothesized first by Carr (1987) with recent work by Polovina et al. (2006) reporting that specific pelagic regions, such as the Kuroshio Extension Bifurcation Region of the North 
Pacific Ocean, may be an important nursery habitat for juvenile loggerhead turtles.

Previous studies using satellite tags affixed to juvenile loggerheads in the North Pacific have found that during the first quarter of the year these turtles occupy a northern latitude range from $28^{\circ}$ to $36^{\circ} \mathrm{N}$ (Polovina et al. 2004). This area corresponds to the North Pacific Transition Zone (NPTZ), a region which separates the North Pacific Subarctic and Subtropical Gyres. To the south, the transition zone is bounded by the North Pacific Subtropical Frontal Zone (NPSTFZ), which is identified in winter by the $18^{\circ} \mathrm{C}$ isotherm (Roden 1980, 1991). Within the transition zone, loggerheads were found to be associated with the biological feature described as the Transition Zone Chlorophyll Front (TZCF) (Polovina et al. 2001, 2004, 2006), an important migration and forage pathway for many pelagic animals (Polovina et al. 2001) which is associated with the $18^{\circ} \mathrm{C}$ isotherm in the central North Pacific (Bograd et al. 2004). The TZCF is most commonly used as an indicator of this highly convergent area in the frontal zone, with increased accumulation of organic matter and sessile organisms. A diet study of juvenile loggerheads in the central North Pacific showed that 4 of the 5 major prey items for these individuals were neustonic species that would tend to concentrate in a highly convergent area such as a frontal zone (Parker et al. 2005). Juvenile loggerhead turtles tend to stay within waters close to the surface in this region. Diving results from an archival tag affixed to a $61 \mathrm{~cm}$ straight carapace length (SCL) loggerhead turtle in the NPTZ showed the turtle spending most of its time in the top $50 \mathrm{~m}$ during the day and night in the first quarter of the year, with minimal time spent below $100 \mathrm{~m}$ (Polovina et al. 2003). Based on these studies, it is clear that the NPTZ, especially the $18^{\circ} \mathrm{C}$ isotherm demarcating the NPSTFZ, is an important migration and forage area for juvenile loggerhead turtles. This type of thermal habitat demarcation has also been seen for leatherback turtles Dermochelys coriacea in the North Atlantic. Satellite tracking results indicated that leatherback turtles in this region could be encapsulated by the $15^{\circ} \mathrm{C}$ isotherm (McMahon \& Hays 2006), while a more recent study using leatherback sightings, strandings, and captures suggested that surface waters of 10 to $12^{\circ} \mathrm{C}$ were indicative of the lower threshold to prolonged occupation (Witt et al. 2007).

The Hawaii-based longline fishery operates year round in the area $180^{\circ}-140^{\circ} \mathrm{W}, 0^{\circ}-40^{\circ} \mathrm{N}$, targeting billfish and tuna species. Historically, during the first half of the year, the fishery has specifically targeted swordfish Xiphias gladius to the north of the Hawaiian Islands in the NPSTFZ (Seki et al. 2002). Swordfish sets are generally set during the night, with the fishing gear configured to lie shallower in the water column than deep sets targeting tuna species (Boggs 1992, Ito 1998). Preliminary observations by time-depth recorder measurements from commercial longlines indicated that the mean depth of the deepest hook was $70.6 \mathrm{~m}$ (Bigelow et al. 1999, C. Boggs, NMFS Pacific Islands Fisheries Science Center, unpubl. data). Combined, these operational fishery parameters place a large number of hooks on shallow sets less than $100 \mathrm{~m}$ in depth in the NPSTFZ during the first quarter of the year in the same temporal and spatial position as juvenile loggerhead sea turtles.

The importance of understanding and minimizing the bycatch of loggerhead turtles by the pelagic longline fisheries has been well documented (DiNardo 1993, Ito 1998, Lewison et al. 2004, Gilman et al. 2007, Lewison \& Crowder 2007). Increasing numbers in the bycatch of loggerhead turtles by the Hawaii-based longline fishery during the 1990s led to temporary time-area closures in the early 2000s and the subsequent ban of all shallow sets by the Hawaii longline fishery in 2002. The shallow set fishery was reopened in late 2004 but as a limited entry fishery with several gear requirements in place. This included the use of larger circle hooks in an attempt to decrease the ingestion of hooks by sea turtles, a limit of 2120 shallow sets per year, and the additional requirement of $100 \%$ coverage of these shallow sets by observers (NMFS 2004). A take limit of 17 interactions with loggerhead turtles was also put into place, with a closure of the fishery for the remainder of the year in effect when this limit was reached. In March 2006, the 17 loggerhead turtle-take limit was reached, forcing the closure of the shallow set portion of the fishery for the remainder of the year. This repercussion increased awareness on the part of both fishers and managers of the importance of the first quarter of the year to the Hawaii-based longline shallow set fishery.

In response to the fishery closure, a project was initiated to create a dynamic product showing the highest areas of potential loggerhead turtle bycatch based on analysis of historical data and the environment. The goal of this project was to create a timely, sciencebased tool for recommendation which would be easily usable and understandable by fishers and management entities. An inter-disciplinary approach involving fishery, oceanographic, and satellite tracking data was used to aid in quantifying the relationship between habitat and loggerhead bycatch (Godley et al. 2008). The present paper describes the scientific analysis used to create the experimental product named TurtleWatch, a map providing up-to-date information about the thermal habitat of loggerhead sea turtles in the Pacific Ocean north of the Hawaiin Islands, as well as the changes in fishing behavior or loggerhead interactions observed after the release of the TurtleWatch product. 


\section{MATERIALS AND METHODS}

The purpose of this study was to better understand where turtle interactions may have occurred, based on available spatial and environmental data. To accomplish this, data on fishing locations and dates were imperative to match fishing activity to a corresponding environmental variable, which in this study was water temperature. Information on any interactions with loggerheads was also essential, as this would allow for the matching of an interaction position in time with the corresponding sea surface temperature (SST) signal.

Fisheries data. The fishing data used in this study were obtained from 2 logbook sources, with data recorded by either fishers or federal observers depending on the data type. The Hawaii Longline Observer Program was established in March 1994 for the purpose of monitoring interactions between the longline fishery and sea turtles (DiNardo 1993, Walsh et al. 2005). During each observed set, observers monitor sets and record and log a large array of information on set, gear configuration, catch, protected species interactions (i.e. bycatch), and other environmental and operational parameters. In the present study, information on loggerhead interactions from 1994 to 2007 was used. In the period prior to shallow set regulation, i.e. between 1994 and 2002, observer coverage of shallow sets varied considerably. Observers were randomly placed aboard commercial fishing vessels targeting swordfish (DiNardo 1993), with an average of $36 \%$ of the active vessels carrying an observer at least once a year prior to 2000 (Walsh et al. 2005) and the observer coverage of sets remaining below $5 \%$. Observer coverage levels increased after 2000, but coverage levels were around 20 to $25 \%$ until after the shallow set fishery was reopened in 2004, when it was federally mandated that an observer be present to monitor all shallow sets deployed by the Hawaii-based longline fishery. This results in a dataset of loggerhead interactions representing a pre-legislation period in the years 1994 to 2002 with a smaller percentage of sets observed, and a post-regulation period from 2005 to 2007 with $100 \%$ of all sets observed.

Under a federal mandate, all information for each individual commercial longline set must be recorded onto a logbook page. The primary objective of the logbook system, implemented in November 1990, is to obtain statistically reliable information on (1) fishing effort and catch and (2) the take of protected species. These logbook reports then provide information comparable to information available from the observer logbooks such as set date, location, effort, and bycatch of protected species during the period from November 1990 through the present. However, a study comparing estimates of turtle take rate between logbook data reports and scientifically observed sets showed that the observed turtle take rate was considerably higher by observers than that reported by fishers in the logbook (DiNardo 1993). Because the reported takes of protected species were likely downwardly biased from non-reporting, only operational fishery information (e.g. hooks, set time) was used from the longline logbooks in the present study to provide data from 1994 through June 2002, when the ban on shallow sets was put into place. These data were coupled with the postban 2004 to 2007 observer reports, which provided a complete record of all set date, location, and effort for shallow sets from 1994 through 2007.

Data from both the federal logbooks and observer reports were filtered to focus on shallow sets targeting swordfish. Longline logbook data from 1994 to 2002 were filtered by only retaining sets that were classified at that time as either shallow or mixed sets. The mixedset operations were mostly shallow set, and under current regulations all sets must be either shallow or deep. For each interaction, when available, the date and location coordinates of the turtle take were used. For the fishing sets, the date of the beginning of the haul was used along with the average of the beginning and ending haul coordinates. This was done to attempt the closest match of fishing sets and turtle interactions, as turtle captures were only recorded during the hauling of the gear. For 21 interactions no capture date or position was recorded, but the trip number and set number were available. For these interactions the trip number and set number from the interaction record were matched to the corresponding set information from the logbooks. The longline logbook haul date and average haul coordinates were then used.

We included any reported interactions of unidentified hardshell turtles in the present study, as these interactions are conservatively used in the interaction tally in the decision to close the shallow set fishery (because the great majority of hardshell turtles from shallow sets are loggerheads). For example, in 2006, 2 interactions were reported as unidentified hardshell, yet were added to the 15 reported loggerhead turtle interactions to bring the count to the 17 turtle limit.

Satellite tag data. Data from wild-caught and captive-reared turtles were used to represent fisheryindependent locations of loggerhead turtles. Turtles were outfitted with satellite transmitters attached to the dorsal carapace using the procedures outlined in Balazs et al. (1996) and equipped with Telonics model ST-18, ST-19, ST-24, Wildlife Computers SDR-T10, SDR-T16 or SPOT3 Argos-linked satellite transmitters. Locations were transmitted to ARGOS processors aboard NOAA polar orbiting satellites according to the tag's set duty cycle resulting in a time series of positions with an associated quality flag assigned by 
ARGOS. Positions were screened using the methods described in Kobayashi et al. (2008) with only the highest quality position data with likely swimming velocities kept in the final data. This resulted in 10778 unique positions from 105 individual turtles and covered the 1997 to 2006 time period.

Environmental data. SST data were derived from the 5-channel Advanced Very High Resolution Radiometers (AVHRR) on board the NOAA-7, $-9,-11$, and -14 polar orbiting satellites. The data used from 1985 to July 2003 were obtained from the descending (nighttime) passes that were processed using versions 4.0 and 4.1 of the AVHRR Pathfinder SST algorithms developed by the University of Miami (Vazquez et al. 1998). These data are received as a $9 \mathrm{~km}$ product mapped to an equal area projection for each $8 \mathrm{~d}$ period. From July 2003 to the present, daily SST data processed using the National Environmental Satellite, Data, and Information's (NESDIS) global area coverage (GAC) algorithm were averaged to create weekly and monthly images that are comparable on a temporal and spatial resolution to the Pathfinder V4 SST product $\left(\mathrm{r}^{2}=0.99, \mathrm{p}<0.01\right)$. The SST used in the TurtleWatch product was a daily, $3 \mathrm{~d}$ temporal mean image of the temperature field processed using the GAC algorithm.

Sea surface height ( $\mathrm{SSH}$ ) data were mapped at a global $0.3 \times 0.3^{\circ}$ resolution with orbit error reduction provided by the Ssalto program of the Centre National d'études Spatiales, France. This altimetry product is a weekly average of the measured along-track sea level profiles mapped to a mercator projection. The average of these along-track profiles from 1993 to 1998 was used to create a mean profile that was then subtracted from the mapped product to obtain the sea level anomalies. For the October 1992-July 2002 time period, data from the TOPEX/POSEIDON altimeter were used. After July 2002, JASON-1 was put into operation along the same orbit as TOPEX/POSEIDON, and since then its data were used in the study. To compute the geostrophic currents, the 1994 NODC World Ocean Atlas Levitus long-term mean $1000 \mathrm{~m}$ dynamic height data set was added to the SSH anomaly files to create an 'absolute' SSH. The east-west and north-south gradients were derived from this height and subsequently used to calculate the east-west and northsouth components of the geostrophic current, as described in Polovina et al. (1999).

Data analysis. To identify the thermal region where loggerhead interactions and shallow sets occurred, the averaged position data of shallow sets and loggerhead turtle interactions were matched in time and space to the $8 \mathrm{~d}$ remotely sensed SST, which was the highest temporal and spatial temperature data available at the time of the analysis. Data was matched at each individual location using the bilinear interpolation method in the routine grdtrack, which is part of the Generic Mapping Tools software package (Wessel \& Smith 1991) available free of charge at http://gmt.soest.hawaii. edu. Using this method, temperature values were obtained for every position of each shallow set, loggerhead turtle interaction, and ARGOS-processed transmission of tagged turtles. Tests for normality were performed using the Kolmogorov-Smirnov (K-S) goodness of fit test (Zar 1984) in MATLAB (Math Works) (K-S test).

\section{RESULTS}

\section{Fishery information}

Table 1 provides information on the number of sets, hooks, and associated loggerhead turtle interactions for the first quarters from 1994 through 2006. Over the entire time period, 9888 shallow sets were made by the fishery in the first quarter, with a total of 7927891 hooks deployed and 149 loggerhead interactions occurring. The maximum percentage of historical effort is north of the Hawaiian Islands, with a large percentage occurring in the transition zone north of $30^{\circ} \mathrm{N}$ during this period. The spatial pattern of the fishery in the transition zone follows an apparent diagonal axis with effort distributed from the northeast to the southwest (Fig. 1). There was a definite shift in the focus of the effort to the north after the reopening of

Table 1. Total operational fishery and loggerhead turtle interaction (LH int) parameters for January-March during the pre(1994-2002) and post- (2005-2006) regulation periods. The values in parentheses represent the percentage north of $28^{\circ} \mathrm{N}$. Q1 represents the January-March combined totals

\begin{tabular}{|lccccccc|}
\hline \multirow{2}{*}{ Total for } & \multicolumn{4}{c}{$1994-2002$} & & & \multicolumn{2}{c|}{$2005-2006-1$} \\
\cline { 2 - 4 } & Sets & Hooks & LH int & & Sets & Hooks & LH int \\
\hline Jan & $2569(69.7 \%)$ & $2134548(68.1 \%)$ & $43(38)$ & & $255(100 \%)$ & $214281(100 \%)$ & $8(8)$ \\
Feb & $2322(82.3 \%)$ & $1832153(80.7 \%)$ & $40(39)$ & & $483(99.8 \%)$ & $407196(99.8 \%)$ & $15(15)$ \\
Mar & $3516(88.1 \%)$ & $2803598(87.1 \%)$ & $28(28)$ & & $653(95.7 \%)$ & $536115(95.5 \%)$ & $15(14)$ \\
Q1 & $8497(80.8 \%)$ & $6770299(79.4 \%)$ & $111(105)$ & & $1391(97.9 \%)$ & $1157592(97.8 \%)$ & $38(37)$ \\
\hline
\end{tabular}




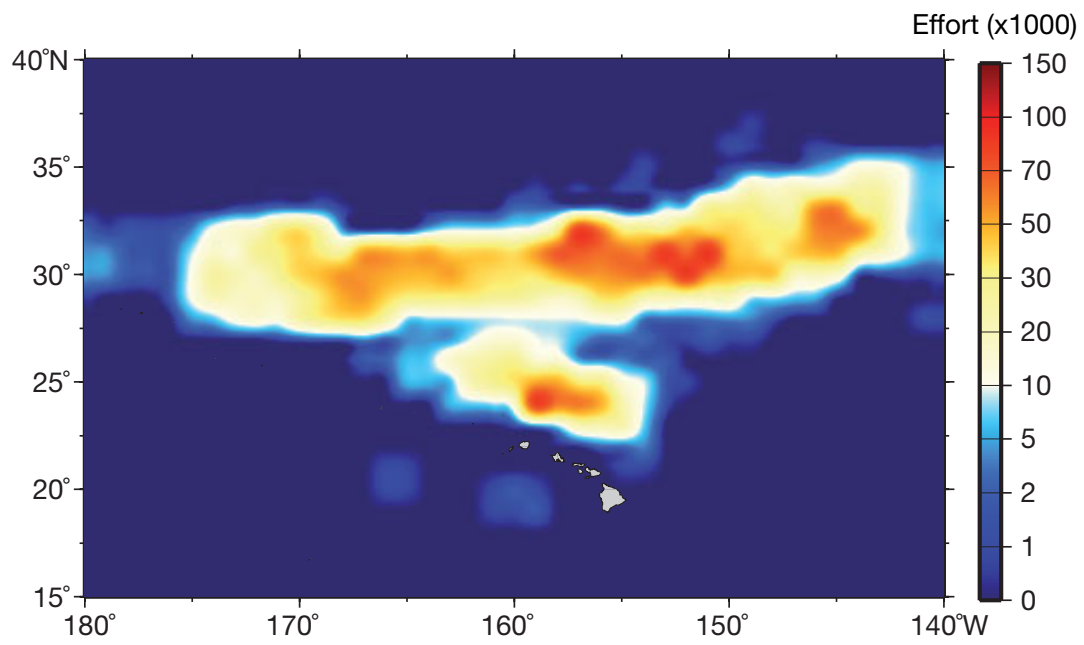

Fig. 1. Pseudo-color representation of the total number of hooks (effort) deployed in shallow sets by the Hawaii longline fishery during the first quarters of 1994 to 2006. Data was binned to $1 \times 1^{\circ}$ grid cells and then filtered due to confidentiality requirements. Colors represent the total effort for a $1 \times 1^{\circ}$ region, not an individual pixel

the fishery in late 2004 , with $98 \%$ of the effort distributed north of $28^{\circ} \mathrm{N}$ during the first quarters of 2005 to 2006 as compared to the pre-closure period, when $79 \%$ of the effort was north of $28^{\circ} \mathrm{N}$ during the first quarter (Table 1). Of all turtle interactions, $58.1 \%$ occurred in the first quarter during the pre-regulation period, with $94.6 \%$ of these first quarter interactions in latitudes north of $28^{\circ} \mathrm{N}$. For the post-regulation period, $89.7 \%$ of all turtle interactions were in the first quarters of 2005 to 2006 , with $100 \%$ of these interactions occurring in latitudes north of $28^{\circ} \mathrm{N}$.

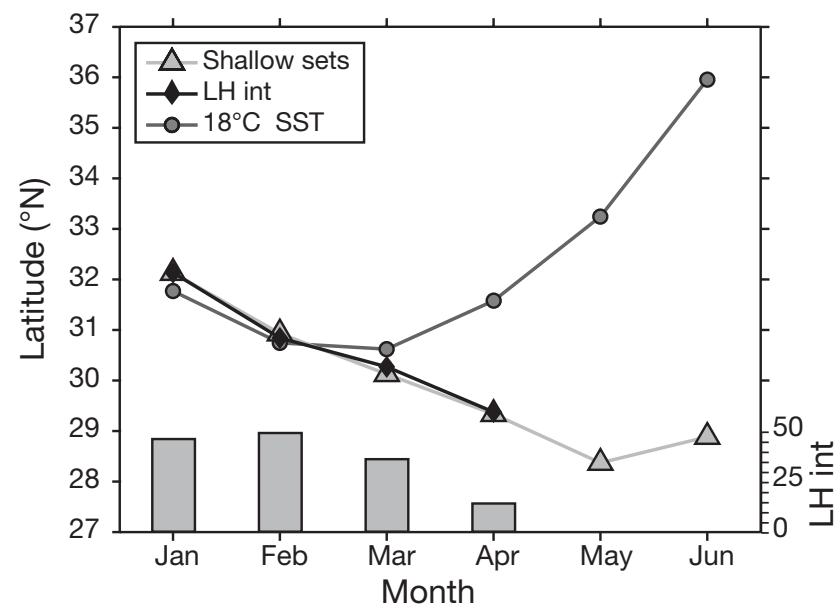

Fig. 2. Relationship between month and average latitude of shallow sets, loggerhead turtle interactions (LH int), and the North Pacific Subtropical Frontal Zone (represented by the $18^{\circ} \mathrm{C}$ isotherm proxy averaged from $180^{\circ}-150^{\circ} \mathrm{W}$ ) for 1994 to 2006. Bar plot at the bottom represents the total number of LH int for each month over the period 1994 to 2006. SST: sea surface temperature

\section{Environmental relationship between sets and loggerhead interactions}

There is a strong relationship between the average latitudinal position of the $18^{\circ} \mathrm{C}$ isotherm shallow sets and loggerhead turtle interactions for all first quarters during the period 1994 to 2006 (Fig. 2). During these first 3 mo, shallow sets as well as turtle positions closely track the latitudinal movement of the $18^{\circ} \mathrm{C}$ isotherm, which here is used as a proxy for the central location of the NPTZ. Beginning in April, the fishery moves to the south of the rapidly northward moving frontal zone, with a marked decrease in loggerhead turtle interactions. The divergence of the fishery and the frontal zone continues through May and June, with no loggerhead turtle interactions occurring above $28^{\circ} \mathrm{N}$ in these months.
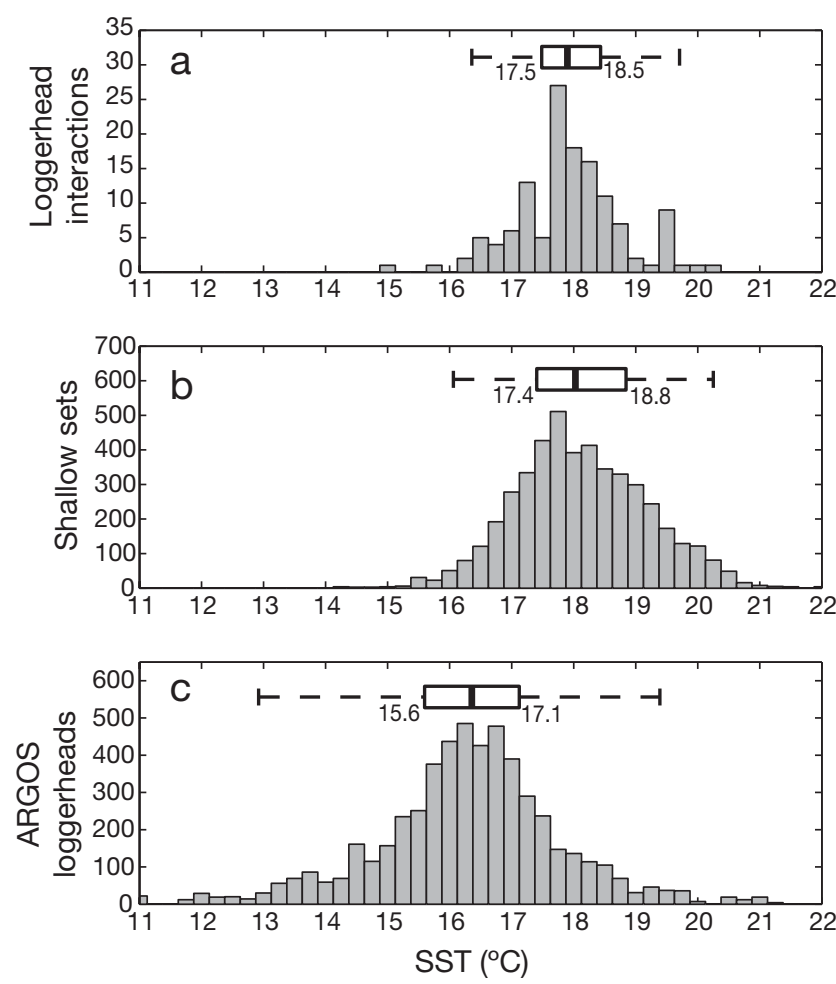

Fig. 3. Frequency distributions of sea surface temperature (SST) associated with positions of (a) loggerhead turtle interactions with the shallow set fishery, (b) shallow sets deployed by the fishery and (c) loggerhead turtles recorded by satellite tags. Solid line in the box and whisker diagrams represents the median, with the box representing the 25th and 75th percentiles, and the dashed line the range covering $95 \%$ of the data. Annotated numbers represent the SST values corresponding to the 25th and 75th percentiles of the distribution 
Analysis of the temperature ranges associated with loggerhead turtle interactions, shallow sets, and turtle positions from satellite tags showed the overlap in thermal range across these 3 distributions (Fig. 3). SST values associated with loggerhead turtle interactions for the first quarters in 1994 to 2006 ranged from 15.1 to $20.1^{\circ} \mathrm{C}\left(\right.$ mean $\left.=17.9^{\circ} \mathrm{C}, \mathrm{SD}=0.8^{\circ} \mathrm{C}\right)$. The distribution of SST values relating to the position of shallow sets in the first quarter was similar to that of the interactions, ranging from 14.1 to $21.9^{\circ} \mathrm{C}$, with a slight skew towards warmer SST values (mean $=18.1^{\circ} \mathrm{C}, \mathrm{SD}=$ $1.0^{\circ} \mathrm{C}$ ) (Fig. 3b). The distribution of SST associated with turtles affixed with satellite tags was much cooler overall, with a wider range from 11 to $21.6^{\circ} \mathrm{C}$ (mean $=$ $16.3^{\circ} \mathrm{C}, \mathrm{SD}=1.6^{\circ} \mathrm{C}$ ) (Fig. $3 \mathrm{C}$ ).

The SST distribution for loggerhead turtle interactions was non-normal (K-S test, p < 0.01). The 50\% (interquartile) and $95 \%$ percentile ranges for all 3 distributions are shown in Fig. 3. The interquartile range of SST for all loggerhead interactions in the first quarter for all fishing years in 1994 through 2006 was 17.5 to $18.5^{\circ} \mathrm{C}$ (Fig. 3a), which represents the SST range where $50 \%$ of all interactions occurred during this time period. This temperature range was used as the basis for a thermal warning band of avoidance to aid in the de- crease of loggerhead turtle interactions by the shallow set fishery. As a result of the observed cooler SST distribution of fishery-independent turtle locations (from wild-caught and captive-reared turtles), the lower bound of the interquartile range was used as a northern recommended limit for the setting of shallow gear in the first quarter of the calendar year. As the metric system is not yet employed by the Hawaii-based longline fishery, the $18.5^{\circ} \mathrm{C}$ recommended value was converted to degrees Fahrenheit and rounded to the closest $0.5^{\circ} \mathrm{F}$. This translates into a value of $65.5^{\circ} \mathrm{F}$ which was used in conjunction with ocean currents to create the initial experimental product released as TurtleWatch (Fig. 4), a thermal map produced on a daily basis that covers the spatial area of greatest historical effort. Ocean currents were added at the request of the industry to aid in the selection of appropriate fishing conditions.

\section{Comparison of sets pre- and post-TurtleWatch}

Data from 2005 to 2007 , in which $100 \%$ of all interactions were recorded, were analyzed to reveal changes in the location of the fishery in the season after the release of TurtleWatch in December 2006. The opera-

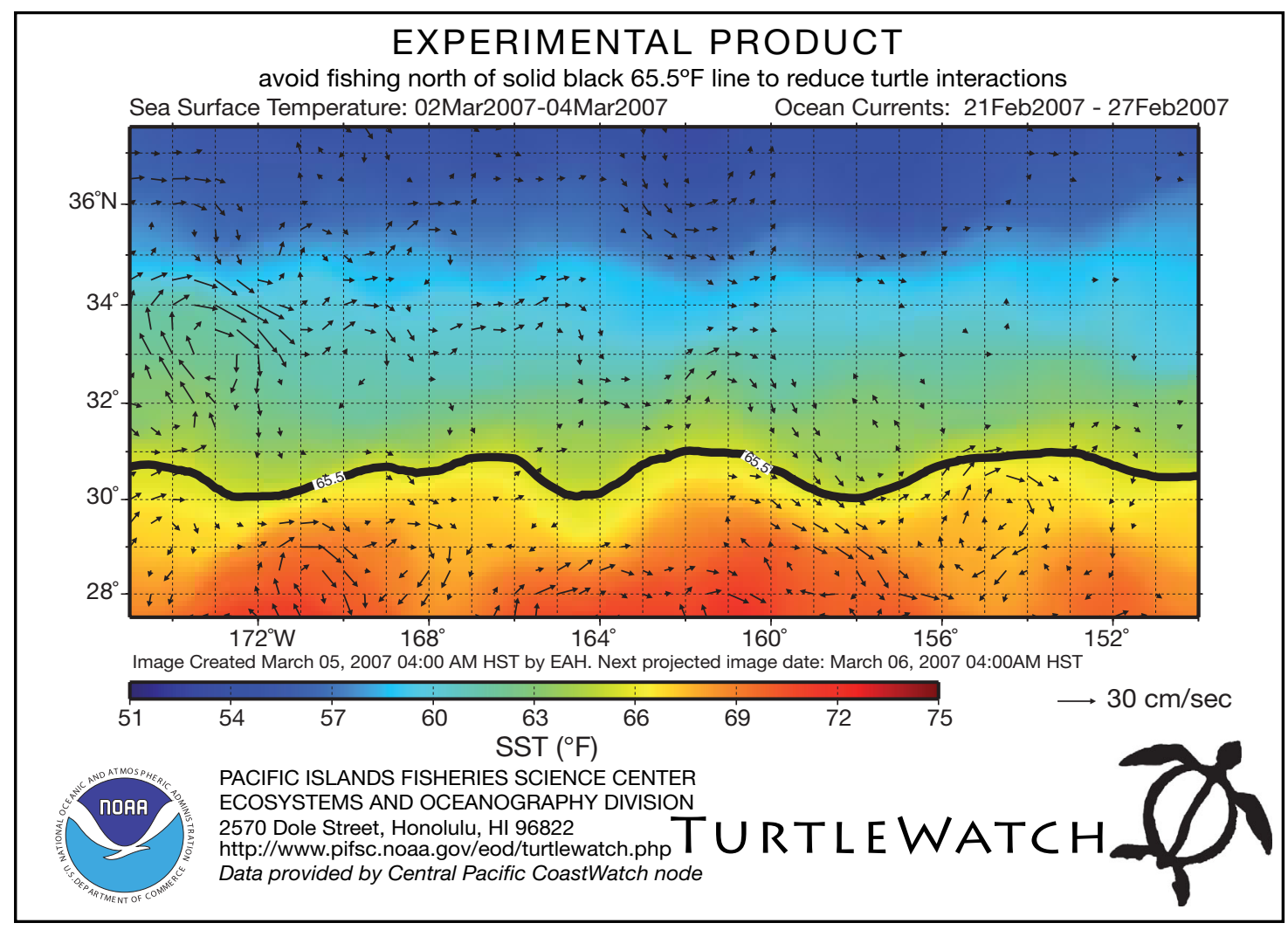

Fig. 4. The TurtleWatch product. Pseudo-color image represents the sea surface temperature (SST) field ( $\left.{ }^{\circ} \mathrm{F}\right)$. Black arrows represent the magnitude and direction of the geostrophic currents derived from altimetry data. The black line represents the $65.5^{\circ} \mathrm{F}$ $\left(\sim 18.5^{\circ} \mathrm{C}\right)$ isotherm 
Table 2. Total operational fishery and loggerhead turtle interaction parameters for sets $>28^{\circ} \mathrm{N}$ in January-March during the post-regulation (2005-2007) period

\begin{tabular}{|c|c|c|c|c|c|c|c|c|c|}
\hline & \multicolumn{3}{|c|}{-2005} & \multicolumn{3}{|c|}{-2006} & \multicolumn{3}{|c|}{-2007} \\
\hline & Jan & Feb & Mar & Jan & Feb & Mar & Jan & Feb & Mar \\
\hline Sets & 62 & 173 & 285 & 193 & 309 & 340 & 236 & 282 & 279 \\
\hline Hooks & 49695 & 141940 & 237945 & 156136 & 238144 & 276634 & 202832 & 243027 & 243627 \\
\hline No. of interactions & 1 & 7 & 1 & 7 & 3 & 7 & 0 & 5 & 7 \\
\hline Interaction rate & 0.0201 & 0.0493 & 0.0042 & 0.0448 & 0.0126 & 0.0253 & 0.0000 & 0.0206 & 0.0287 \\
\hline
\end{tabular}

tional fishery information and loggerhead interactions for the first quarter for each of these years are displayed in Table 2. The greatest number of hooks during this 3 yr period was deployed by the fishery in the first quarter of 2007. Effort by the fishery was more evenly spread out across the 3 mo period during 2007 , in contrast to the increase in effort from January through March in 2005 and 2006. The lowest average interaction rate for the first quarter of the $3 \mathrm{yr}$ period was in 2007. The hard cap of 17 turtle interactions was reached in March 2006, compared to 12 interactions reported in 2007 . The largest variability in turtle interactions by month was in January.

There was an apparent geographic shift in the placement of the sets in 2007, with the majority of the sets in January occurring north of $33^{\circ} \mathrm{N}$ (Fig. 5). This was similar to the latitudinal position of the sets in 2005, yet much farther to the north than the sets in January 2006. In addition to sets occurring farther to the north in the beginning of the first quarter, the fishery did not begin its southern movement until late in January, in contrast to the observed movement to the south during mid-January 2005 and 2006. Eight of the 12 turtle interactions $(66.7 \%)$ in the first quarter of 2007 occurred in surface waters colder than $18.5^{\circ} \mathrm{C}$ and in the area where fishing was discouraged by the TurtleWatch product during that time period.

The interannual variability in the NPTZ defined during the month of January from 2005 to 2007 is shown with the main area of shallow set placement and reported turtle interactions in Fig. 6. The axis and latitudinal position of the area between the 17.5 and $18.5^{\circ} \mathrm{C}$ isotherms was substantially different in 2005 than in the following $2 \mathrm{yr}$. In 2005, the frontal zone was farther to the north in the east and farther to the south in the west in January (Fig. 6a) and continuing though February and March. The placement of shallow sets by the fishery was also very different in 2005 than the other 2 yr. The smaller number of sets was more broadly distributed, with no apparent core area fished. The position and axis of the frontal zone was very similar in 2006 and 2007 with a more constant latitudinal positioning during January (Fig. 6b,c) and continuing through February and March. While the axis and position of the frontal zone were very similar in 2006 and 2007, the core location of shallow set placement was not. In 2006, shallow sets were placed in 2 locations: one area to the northeast and a larger core area in the central area of the frontal zone directly between the 17.5 and $18.5^{\circ} \mathrm{C}$ isotherms. In contrast to 2006 , the
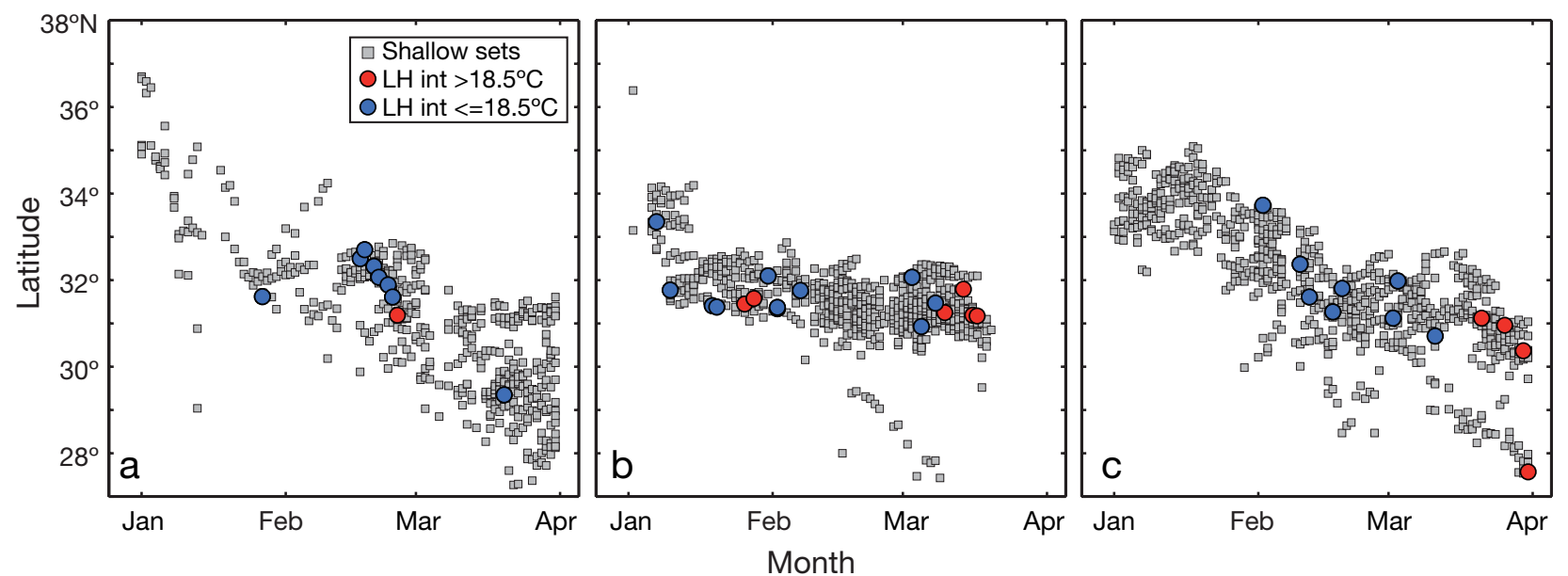

Fig. 5. Change in the latitudinal position of shallow sets and loggerhead turtle interactions (LH int) through the first quarter of the year for (a) 2005, (b) 2006 and (c) 2007. Blue circles $(\mathrm{n}=25)$ : turtle interactions in waters colder than $18.5^{\circ} \mathrm{C} ;$ red circles $(\mathrm{n}=11)$ : interactions in waters warmer than $18.5^{\circ} \mathrm{C}$ 


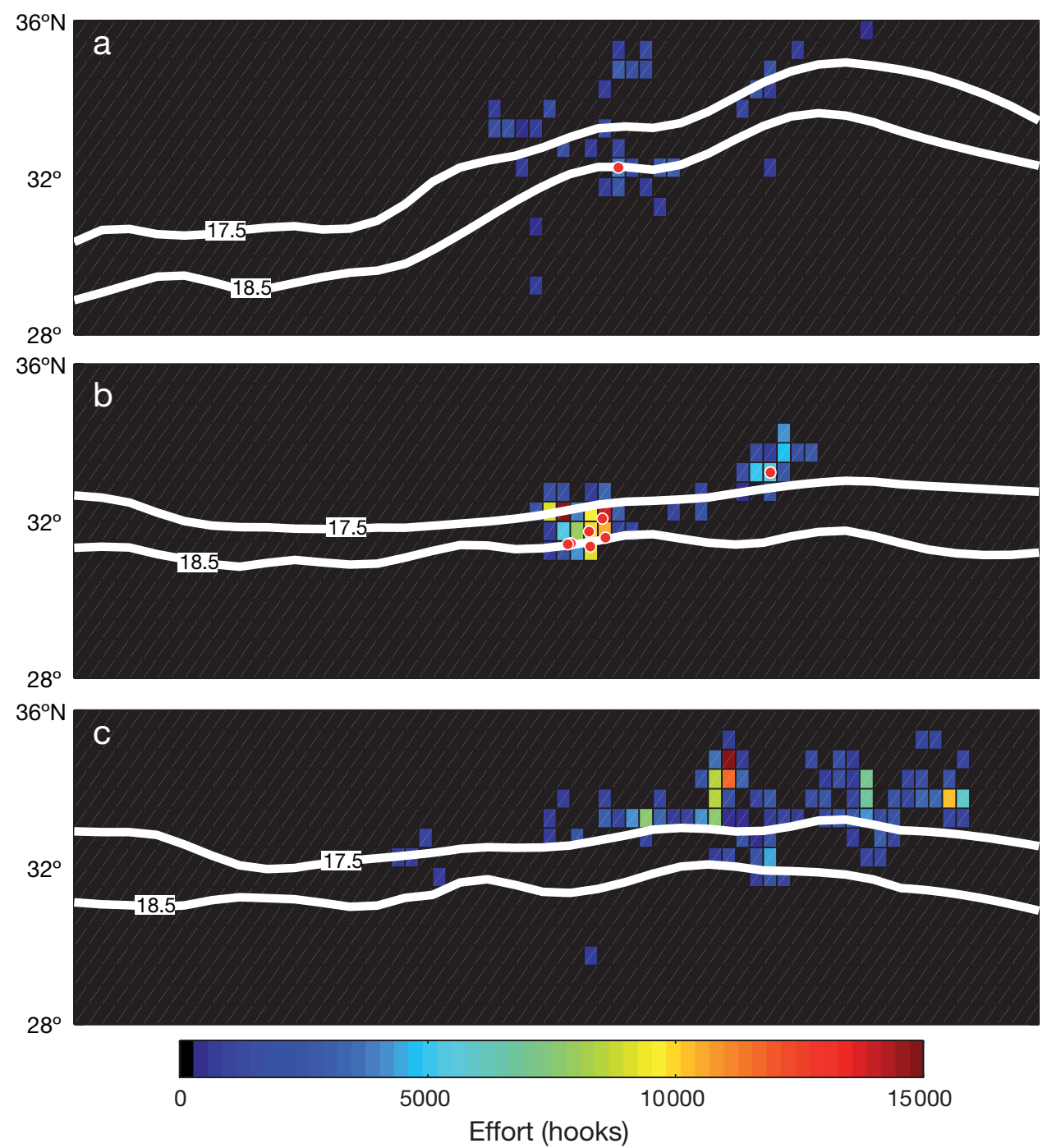

Fig. 6. Spatial position of shallow sets (pseudo-color blocks) and loggerhead turtle interactions (red circles) for January (a) 2005, (b) 2006 and (c) 2007 . White lines: average monthly position of the 17.5 and $18.5^{\circ} \mathrm{C}$ isotherms for each January. Longitude values have been removed because of fishery confidentiality requirements of the data

majority of shallow sets were north of the $17.5^{\circ} \mathrm{C}$ isotherm in January 2007 (Fig. 6c). In all years, the smallest geographic distance between the 17.5 and $18.5^{\circ} \mathrm{C}$ isotherms was in the central portion of the area fished (Fig. 6).

\section{DISCUSSION}

The TurtleWatch product was released on December 26, 2006, to provide information based on the best available science with the aim of decreasing the bycatch of loggerheads in the Hawaii-based pelagic longline fishery. The closure of the shallow set fishery in March 2006, less than 2 yr after its reopening, was a concern both to industry and management. The main purpose of this research was 2-fold: (1) to gain a better scientific understanding of the possible environmental indicators for loggerhead interactions with shallow sets, and (2) to be able to provide a daily product to managers and the industry providing information on the dynamically changing area of high potential interactions during the first quarter of the year.

The combined effect of species overlap, gear restrictions, and increased concerns in regards to bycatch of loggerheads places additional emphasis on attempting to minimize interactions during the first quarter, a time when both the shallow set fishery and loggerheads appear to inhabit the same location near the NPSTFZ (Polovina et al. 2000, 2001, 2004, Seki et al. 2002). The minimization of loggerhead bycatch during the first quarter would allow the shallow set fishery to continue 
later through the year, as well as allow the fishery to begin operations prior to the start of a new year. Therefore, it is critical to have the ability to understand and ultimately map in near real time the area of highest potential loggerhead interactions with the fishery during the first quarter of the year to minimize interactions and allow the continuation of longline operations. Time area closures work in situations where the critical habitat of interest is static through time, a very different scenario from highly variable regions such as frontal zones. When averaged through time, the thermal band between 17.5 and $18.5^{\circ} \mathrm{C}$ may appear closely aligned with a particular latitudinal range, yet any interannual changes in the position of the frontal zone may displace both the loggerhead turtles and the fishery either to the north or to the south. In these cases, there is a movement of the potentially higher interaction area that would be predicted by a dynamic, environmentally based map, yet not possible with a static, geographic time area closure.

The initial TurtleWatch product was created using the maximum amount of data from available sources for the first 3 mo of each year from 1994 to 2006. The first quarter was important since this was the time of both the largest overlap in space between shallow sets, interactions, and the frontal zone (Fig. 2), but high interactions during this period also have consequences for the shallow set fishery during the remainder of the year. The year 2006 was an extreme example of this, as the loggerhead take limit was reached on March 17 , thereby curtailing shallow set fishing during the first half of the year as well as delaying the start of the shallow set fishery until the next calendar year. This results in the first quarter of one year having potential ramifications over 2 seasons for the shallow set fishery.

The data sources used to research the appropriate environmental range were chosen to maximize the available data over the entire time period of interest. The observer logbook data were mandatory as they provided an unbiased total number of recorded loggerhead turtle interactions, yet observer coverage varied through the 1994 to 2002 time period (Walsh et al. 2005), resulting in a partial dataset with regard to operational fishery information. For this reason, the operational data from the commercial fishery logbooks were used to provide the maximum amount of information on shallow sets during the same period. The maximum temporal period of loggerhead turtle positions transmitted from satellite tags occurred from 1997 though 2006. This resulted in a comparison of the fishery-based turtle locations (interactions) with the fishery-independent turtle locations in slightly different temporal periods as there were no satellite locations for the 1994 to 1996 period. This was justified, as results from previous studies clearly showed the persistent association of juvenile loggerhead turtles with specific isotherms within the NPTZ (Polovina et al. 2001, 2004, 2006, Kobayashi et al. 2008). Thus, any interannual variability in the frontal system would result in an associated movement of turtles, resulting in a constant thermal signal over the time period.

The decision to base this initial product solely on temperature was made both to simplify the data requirements necessary to create the product and to be able to use an environmental field familiar to the industry and managers. Fishers targeting swordfish with shallow sets use surface temperature as an indicator to find the optimal placement of gear near oceanic fronts (Ito 1998, Bigelow et al. 1999). Temperature has also been recognized as an important preferred habitat descriptor for loggerhead turtles in the North Pacific Ocean (Kobayashi et al. 2008) as well as for leatherback turtles in the North Atlantic (McMahon \& Hays 2006, Witt et al. 2007). This is not to say that other environmental signals such as ocean color (chlorophyll a) are not an important descriptor of habitat. On the contrary, chlorophyll a fields have also been shown to be an important habitat descriptor (Polovina et al. 2004, 2006, Kobayashi et al. 2008). However, as the main purpose of this product was to provide a near realtime, easily understandable product to managers and the fishery, the addition of chlorophyll data was infeasible as even monthly images may contain a large percentage of cloud cover per image in the NPSTFZ during the first quarter. The ability to solely use SST data allows for a generalization of the product as well, as temperature information is easily available to fishers while at sea via fax or satellite data delivery. This, coupled with the knowledge of the thermal range with the highest probability of loggerhead interactions, allows for fishers to be able to more accurately avoid this high risk area. At the time of the data analysis performed to create the TurtleWatch product, the composite Pathfinder 4/GAC $9 \mathrm{~km} 8 \mathrm{~d}$ SST image provided the best spatial and temporal coverage over the 1994 to 2006 study period. In any study matching a fine scale point in time and space with a broader synoptic field, there is error associated with the movement in both dimensions from the finer point outward. In recent years, refinements to available SST products have improved coverage in both time and space, which may refine the thermal estimates for future turtle interactions.

The initial TurtleWatch product was constructed using the results of the thermal ranges associated with the fishery-dependent and -independent loggerhead locations. The decision to use the $65.5^{\circ} \mathrm{F}\left(\sim 18.5^{\circ} \mathrm{C}\right)$ isotherm as the northern recommended area of fishing was a complex one based on several factors. The interquartile range was chosen as a balance between 
attempting to minimize future bycatch of loggerhead turtles yet accounting for the overlap in the thermal distribution with historical shallow sets by the fishery. The importance of the TZCF to the movement and migration of loggerheads has been documented (Polovina et al. 2001, 2004, 2006), and work by Bograd et al. (2004) found that there was a strong association between the TZCF and SST, specifically the $18^{\circ} \mathrm{C}$ isotherm, in the region north of the Hawaiian Islands. This helps to explain the importance of this surface temperature region to turtles and why a relatively high number of interactions are observed in this narrow thermal range. The idea to use the 95 percentile range was rejected as this would recommend against the deployment of shallow sets in almost the entire frontal zone, which is the area of highest historical use by the Hawaii-based longline fishery (Seki et al. 2002). The initial response was to recommend the avoidance of shallow sets within this thermal band, which would result in a shift in effort to the north and south. Results from the positions of loggerhead turtles affixed with satellite tags, however, showed that during the first quarter these turtles were in a colder surface water habitat. A shift of the fishery to the north may, then, lead to the deployment of shallow sets in an area of higher potential interactions. From these results, the initial experimental product was then built on a recommendation that fishers stay only to the south of the thermal band.

The TurtleWatch product was automatically created daily and delivered both in electronic and paper formats to principal individuals in the industry and management to help ensure proper dissemination. Hard copies of the TurtleWatch product were also delivered daily in conjunction with the delivery of logbook sheets by NOAA personnel to departing vessel captains. This delivery method, then, provided a product with information in a clearly understandable format which could be used in management decisions, thus addressing a concern raised in a recent paper by Godley et al. (2008). TurtleWatch was distributed to all parties with the emphasis that this was an experimental product to be taken under advisement. The results of the fishery locations during the first quarter 2007 clearly show that the fishery did not remain below the recommended isotherm (Fig. 5). Conversely, the fishery was observed to move further north than in previous years and remained to the north for a longer time period than the 2 previous years (Fig. 5). While not entirely unexpected, this movement north, coupled with the location of the frontal zone in 2007, allowed for an opportunity to view the results of a shift in effort to the north of the frontal zone, the region with the highest observed satellite-tagged juvenile loggerhead turtles (Fig. 3). It was interesting to note that increased effort to the north in January had no associated interactions with loggerhead turtles, which is the opposite of what may be expected if potential interactions were expected based on the observed locations of the satellite tagged turtles. One factor of importance for potential interactions may be turtle size. Based on the information of loggerheads in the fishery recorded by observers, interactions to the north occurred with smaller loggerhead turtles. The average size of the turtles affixed with satellite tags in this study was $48.3 \mathrm{~cm}$ on release (Kobayashi et al. 2008), with a large percentage of the satellite tagged turtle positions in the northern portion of the frontal zone in colder surface waters during the first quarter. There are several possible reasons for size-based selection, including changes in the operational aspects of the fishery and differences in diving and/or foraging behavior of the turtles. The average depth range of a $61 \mathrm{~cm}$ SCL loggerhead turtle associated with the frontal zone in the North Pacific was 0 to $60 \mathrm{~m}$ (Polovina et al. 2003). Based on subsurface temperature records in the NPSTFZ during May 1996 to May 1999, the temperature values at $60 \mathrm{~m}$ are close to the $16^{\circ} \mathrm{C}$ isotherm (Seki et al. 2002). If temperature is a limiting factor for juvenile loggerhead turtles, then it may follow that turtles that prefer a surface temperature of $16^{\circ} \mathrm{C}$ may not dive to the same depths as those to the south in warmer surface warmers. A constraint to the surface may minimize the time of overlap with fishery sets which are at depth. Another factor may be that the large circle hooks required by regulations to reduce turtle capture may be more effective on smaller turtles found to the north. Previous research has shown that hook size greatly influences turtle bycatch (Watson et al. 2005).

The majority (65\%) of all loggerhead turtle bycatch in 2007 occurred in the area where fishing was discouraged by the TurtleWatch product. In that respect, the TurtleWatch product was successful in indicating the area where turtle bycatch was most likely to occur, yet highlights that the Hawaii-based longline fleet did not modify its activity to avoid the area of highest potential loggerhead interactions during 2007. A main goal of the TurtleWatch product is to continue to promote the correlation between specific thermal habitat and increased interactions with loggerheads to fishers, with the hope that with this information fishers will voluntarily avoid the areas of highest potential bycatch. Four interactions also occurred late in the first quarter of the year in waters slightly warmer than the frontal zone and just barely south of the TurtleWatch avoidance boundary, where fishing was recommended. A decrease in the bycatch of loggerhead turtles may naturally extend the fishery later into the year. One point that needs to be considered is the seasonal differences in the bycatch of loggerhead turtles by the 
shallow set fishery. The TurtleWatch product was created in response to the relatively high numbers of interactions which occurred in the first quarter of the year and was based on the environmental crossover between loggerheads and the fishery during this time period. As the fishery begins to move to the south later in the year, the frontal zone moves to the north (Fig. 2). Results from satellite tag locations of loggerhead turtles show that a large percentage of the juveniles went north, following the frontal zone in the spring and summer (Polovina et al. 2001, 2006, Kobayashi et al. 2008). This seasonal migration pattern must be explored further to fully understand the potential bycatch of loggerheads in other quarters of the year, as turtles may tend to lag behind the front. This would result in loggerheads occurring in waters in the colder portion of the frontal zone as the front moves south during the first quarter of the year, and occurring in the warmer portion of the frontal zone to the south as the front changes direction and began to move to the north during the second quarter of the year. A better understanding of the movements associated with the frontal zone would result in the ability to better predict the thermal range of highest loggerhead turtle interactions.

\section{CONCLUSIONS}

The TurtleWatch product was an initial effort to help reduce inadvertent interactions between Hawaiibased pelagic longline fishing vessels and loggerhead turtles by providing a near real time product recommending the area in which the deployment of shallow sets should be avoided. Dynamic by nature, a main goal of TurtleWatch was to provide a timely, easily understood and science-based tool to both the industry and managers to aid in decisions regarding the Hawaii-based longline fishery. TurtleWatch was released in December 2006 and was correct in identifying an area where turtle bycatch would more likely occur (i.e. where over $65 \%$ of loggerhead turtle bycatch occurred during the first quarter of the year). In the future, additional refinement of this product to suggest fishing on either side (north or south) of the frontal zone, in addition to increased use of this tool by fishers is predicted to aid in reducing the bycatch of loggerhead turtles.

Acknowledgements. The authors thank Walter Machado, William Walsh, Matthew Parry, Eric Hochberg, Steven Bograd, Daniel Palacios, Naoki Kamezaki, I-Jiunn Cheng, Itaru Uchida, Peter Dutton, as well as Paul Dalzell, Irene Kinan, and Kitty Simonds of the Western Pacific Regional Fishery Management Council, Captain Thaoi Nguyen of the Sea Queen II and Sean Martin of the Hawaii Longline Associ- ation for support and ideas during this research project. Hidetada Kiyofuji, Yonat Swimmer, Michael Seki, Stacy Kubis, Christofer Boggs, and 2 anonymous reviewers provided helpful critiques to improve this manuscript. The authors also thank Lucas Moxey of the NOAA CoastWatch program, Jan Pappas and Karen Sender for additional data support. The lead author also thanks Sei-Ichi Saitoh of the Graduate School of Fisheries Sciences, Hokkaido University for advice and guidance during this project. The Fishery Monitoring and Economics Program (FMEP) of the National Marine Fisheries Service (NMFS), Pacific Islands Fisheries Science Center (PIFSC) in Honolulu, HI, provided the federally mandated longline logbook data. The observer logbook data was provided by the Observer Program at the Pacific Islands Regional Office of the National Marine Fisheries Service in Honolulu, HI. Altimetry data used in this study were produced by the Ssalto program and obtained from Collecte Localisation Satellites (CLS) center under the auspices of the Centre National d'études Spatiales of France (CNSF). The Pathfinder data were distributed by the Physical Oceanography Distributed Active Archive Center of the Jet Propulsion Laboratory. The GAC sea surface temperature data was provided by the NOAA National Environmental Satellite, Data, and Information Service. This research was done as part of the NOAA Fisheries and the Environment (FATE) program. This work was supported partially by the National Aeronautics and Space Administration through a grant provided by the Applied Sciences Program in the Earth Science Division and partially by the National Oceanic and Atmospheric Administration through a grant provided by the bycatch reduction program.

\section{LITERATURE CITED}

Balazs GH, Miya RK, Beavers SC (1996) Procedures to attach a satellite transmitter to the carapace of an adult green turtle, Chelonia mydas. In: Keinath JA, Barnard DE, Musick JA, Bell BA (compilers) Proc 15th Annu Symp on Sea Turtle Biology and Conservation, NOAA Tech Memo, NMFS-SEFSC-387, National Marine Fisheries Service, Miami, FL, p 21-26

Bigelow K, Boggs CH, He X (1999) Environmental effects on swordfish and blue shark catch rates in the US North Pacific longline fishery. Fish Oceanogr 8:178-198

Bjorndal KA (2003) Roles of loggerhead sea turtles in marine ecosystems. In: Bolten AB, Witherington BE (eds) Loggerhead sea turtles. Smithsonian Books, Washington, DC, p 235-254

Boggs CH (1992) Depth, capture time, and hooked longevity of longline-caught pelagic fish: timing bites of fish with chips. Fish Bull (Wash DC) 90:642-658

> Bograd SJ, Foley DJ, Schwing FB, Wilson C and others (2004) On the seasonal and interannual migrations of the Transition Zone Chlorophyll Front. Geophys Res Lett 31:L17204

> Carr A (1987) New perspectives on the pelagic stage of sea turtle development. Conserv Biol 1:103-121

DiNardo G (1993) Statistical guidelines for a pilot observer program to estimate the turtle takes in the Hawaii longline fishery. NOAA Tech Memo, NMFS-SWFSC-190. National Marine Fisheries Service, La Jolla, CA

Dodd, CK Jr (1988) Synopsis of the biological data on the loggerhead sea turtle Caretta caretta (Linnaeus 1758). Biol Rep 88 (14). Fish and Wildlife Service, US Department of the Interior, Washington, DC

Gilman E, Zollett E, Beverly S, Nakano H and others (2007) Reducing sea turtle interactions in the Hawaii-based longline swordfish fishery. Biol Conserv 7:2-23 
Godley BJ, Blumenthal JM, Broderick AC, Coyne MS, Godfrey MH, Hawkes LA, Witt MJ (2008) Satellite tracking of sea turtles: Where have we been and where do we go next? Endang Species Res 4:3-22

Hatase H, Goto K, Sato K, Bando T, Matsuzawa Y (2002) Using annual body size fluctuations to explore potential causes for the decline in a nesting population of the loggerhead turtle Caretta caretta at Senri Beach, Japan. Mar Ecol Prog Ser 245:299-304

Hays GC, Broderick AC, Godley BJ, Luschi P, Nichols WJ (2003) Satellite telemetry suggests high levels of fishinginduced mortality in marine turtles. Mar Ecol Prog Ser 262:305-309

Ito RY (1998) The Hawaii-based longline fishery for swordfish, Xiphias gladius. In: Barrett I, Sosa-Nishizaki O, Bartoo N (eds) Biology and fisheries of swordfish, Xiphias gladius. NOAA Tech Rep NMFS 142. US Department of Commerce, Washington, DC, p 77-88

Kamezaki N, Matsuzawa Y, Abe O, Asakawa H and others (2003) Loggerhead turtles nesting in Japan. In: Bolten AB, Witherington BE (eds) Loggerhead sea turtles. Smithsonian Books, Washington, DC, p 210-217

Kobayashi DR, Polovina JJ, Parker DM, Kamezaki N and others (2008) Pelagic habitat characterization of loggerhead sea turtles, Caretta caretta, in the North Pacific Ocean (1997-2006): insights from satellite tag tracking and remotely-sensed data. J Exp Mar Biol Ecol 356:96-114

Lewison RL, Crowder LB (2007) Putting longline bycatch of sea turtles into perspective. Conserv Biol 21:79-86

- Lewison RL, Freeman SA, Crowder LB (2004) Quantifying the effects of fisheries on threatened species: the impact of pelagic longlines on loggerhead and leatherback sea turtles. Ecol Lett 7:221-231

McMahon C, Hays G (2006) Thermal niche, large-scale movements and implications of climate change for a critically endangered marine vertebrate. Glob Change Biol 12:1330-1338

NMFS (National Marine Fisheries Service) (2004) Fisheries off west coast states and in the Western Pacific; Western Pacific pelagic fisheries; pelagic longline fishing restrictions, seasonal area closure, limit on swordfish fishing effort, gear restrictions, and other sea turtle take mitigation measures. Fed Regist 69:64585-64587

Parker DM, Cooke WJ, Balazs GH (2005) Diet of oceanic loggerhead sea turtles (Caretta caretta) in the central North Pacific. Fish Bull (Wash DC) 103:142-152

Peckham S, Diaz D, Walli A, Ruiz G, Crowder L, Nichols W (2007) Small-scale fisheries bycatch jeopardizes endangered Pacific loggerhead turtles. PLoS One 10:e1401

Polovina JJ, Kleiber P, Kobayashi D (1999) Application of TOPEX/POSEIDON satellite altimetry to simulate transport dynamics of larvae of the spiny lobster (Panulirus marginatus), in the Northwestern Hawaiian Islands, 1993-96. Fish Bull (Wash DC) 97:132-143
Polovina JJ, Kobayashi DR, Ellis DM, Seki MP, Balazs GH (2000) Turtles on the edge: movement of loggerhead turtles (Caretta caretta) along oceanic fronts in the central North Pacific, 1997-1998. Fish Oceanogr 9:71-82

Polovina JJ, Howell E, Kobayashi DR, Seki MP (2001) The Transition Zone chlorophyll front, a dynamic global feature defining migration and forage habitat for marine resources. Prog Oceanogr 49:469-483

Polovina JJ, Howell EA, Parker DM, Balazs GH (2003) Divedepth distribution of loggerhead (Caretta caretta) and olive ridley (Lepidochelys olivacea) turtles in the central North Pacific: Might deep longline sets catch fewer turtles? Fish Bull (Wash DC) 101:189-193

> Polovina JJ, Balazs GH, Howell EA, Parker DM, Seki MP, Dutton PH (2004) Forage and migration habitats of loggerhead (Caretta caretta) and olive ridley (Lepidochelys olivacea) sea turtles in the central North Pacific Ocean. Fish Oceanogr 13:36-51

Polovina JJ, Uchida I, Balazs G, Howell EA, Parker D, Dutton P (2006) The Kuroshio Extension Bifurcation Region: a pelagic hotspot for juvenile loggerhead sea turtles. DeepSea Res II 53:326-339

> Roden GI (1980) On the Subtropical Frontal Zone north of Hawaii during winter. J Phys Oceanogr 10:342-362

Roden GI (1991). Subarctic-subtropical transition zone of the North Pacific: large-scale aspects and mesoscale structure. In: Wetherall JA (ed) Biology, oceanography and fisheries of the North Pacific Transition Zone and the Subarctic Frontal Zone. NOAA Tech Rep NMFS 105: $1-38$

Seki MP, Polovina JJ, Kobayashi DR, Bidigare RR, Mitchum GT (2002) An oceanographic characterization of swordfish (Xiphias gladius) longline fishing grounds in the springtime subtropical North Pacific. Fish Oceanogr 11:251-266

Vazquez J, Perry K, Kilpatrick K (1998) NOAA/NASA AVHRR Oceans pathfinder Sea Surface Temperature Data Set. User's Reference Manual Version 4.0. JPL Publication D-14070, Pasadena, CA

Walsh WA, Ito RY, Kawamoto KE, McCracken M (2005) Analysis of logbook accuracy for blue marlin (Makaira nigricans) in the Hawaii-based longline fishery with a generalized additive model and commercial sales data. Fish Res 75(1-3):175-192

Watson J, Foster D, Epperly S, Shah A (2005) Fishing methods to reduce sea turtle mortality associated with pelagic longlines. Can J Fish Aquat Sci 62:965-981

Wessel P, Smith WHF (1991) Free software helps map and display data. Eos Trans AGU 72:441

Witt MJ, Broderick AC, Johns DJ, Martin C, Penrose R, Hoogmoed MS, Godley BJ (2007) Prey landscapes help identify potential foraging habitats for leatherback turtles in the NE Atlantic. Mar Ecol Prog Ser 337:231-243

Zar JH (1984) Biostatistical analysis, 2nd edn. Prentice Hall, Englewood Cliffs, NJ

Submitted: December 13, 2007; Accepted: April 7, 2008

Proofs received from author(s):June 17, 2008
Editorial responsibility: Brendan Godley,

University of Exeter, Cornwall Campus, UK 